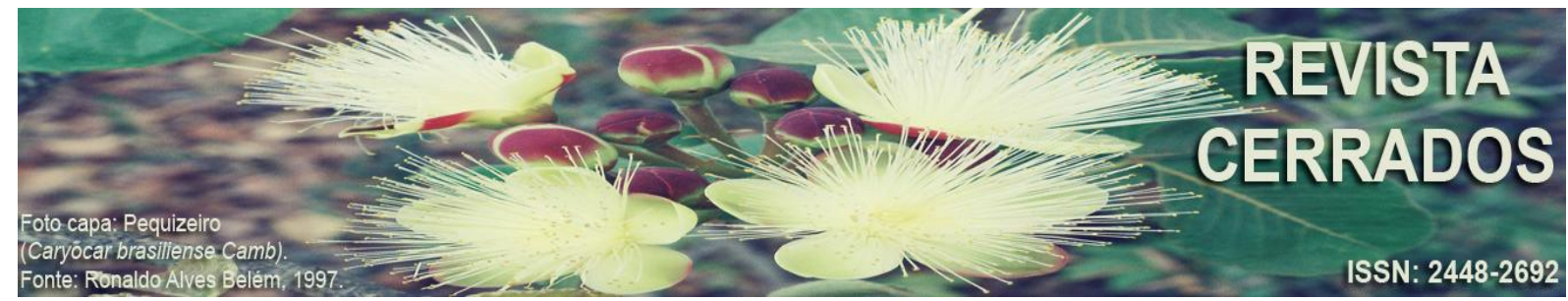

\title{
DESVELANDO HERANÇAS, TRADIÇÕES E PRÁTICAS DE JOVENS
} DE JAPARATUBA/SE-BRASIL

\section{REVEALING HERITAGES, TRADICIONS AND PRACTICES OF UONG PEOPLE FROM JAPARATUBA/SE-BRAZIL}

\section{DESCUBRIENDO HERENCIAS, TRADICIONES Y PRÁCTICAS DE LOS JOVENES JAPARATUBA/SE-BRASIL}

\author{
Maria Augusta Mundim Vargas \\ Universidade Federal de Sergipe - UFS \\ E-mail: <guta98@ hotmail.com.br>.
}

\begin{abstract}
Resumo
Este estudo traz o desenvolvimento de oficinas realizadas com jovens objetivando demonstrar uma metodologia aplicada a levantamentos e análises das expressões culturais. Para tal, apresenta-se, aqui, a evolução das diversas técnicas e instrumentais utilizados desde 2009, ressaltando sua abordagem qualitativa, as vantagens de se realizar em curto espaço de tempo e as possibilidades de aplicação em outros estudos. Ademais, o texto registra como a vivência permitiu apreender seus referentes patrimoniais e identitários e construir uma cartografia cultural referenciada pelos conteúdos levantados e pelas técnicas executadas na oficina.
\end{abstract}

Palavras-chave: Expressões culturais; Patrimônio; Identidade; Metodologia qualitativa; Cartografia cultural.

\begin{abstract}
The text brings the development of a workshop held with young people in order to demonstrate a methodology applied to surveys and analyzes of cultural expressions. To this end, it presents the evolution of several techniques and instruments used since 2009, highlighting its qualitative approach, the advantages of performing in a short time and the possibilities of application in other studies. It shows how the conviviality and the experience made it possible to apprehend their patrimony and identity referents and build a cultural cartography referenced by the contents raised and by the techniques performed in the workshop.
\end{abstract}


Keywords: cultural expressions; patrimony; identity; qualitative methodology; cultural cartography.

\section{Resumen}

Este estudio trae el desarrollo de talleres realizados con jóvenes con el objetivo de demostrar una metodología aplicada a levantamientos y análisis de las expresiones culturales. Para ello, se presenta, aquí, la evolución de las diversas técnicas e instrumentales utilizados desde 2009, resaltando su abordaje cualitativo, las ventajas de realizarse en curto espacio de tiempo y las posibilidades de aplicación en otros estudios. Además, el texto registra como la vivencia permitió aprehender sus referentes patrimoniales e de identidad e construir una cartografía cultural referenciada por los contenidos analizados y por las técnicas ejecutadas en el taller.

Palabras clave: Expresiones culturales; Patrimonio; Identidad; Metodología cualitativa; Cartografía cultural.

\section{INTRODUÇÃO}

Nossas recentes reflexões sobre a inserção das dimensões da cultura em políticas de desenvolvimento resultam de nossas indagações com relação à dinâmica territorial do litoral sergipano - Brasil: i) verificamos como a base socioeconômica das comunidades litorâneas tradicionais vem sendo impactada por grandes empreendimentos implantados nas últimas décadas ${ }^{1}$; ii) questionamos o quanto as dimensões da cultura não são consideradas pelas políticas públicas na avaliação dos impactos decorrentes desses empreendimentos; iii) propomos o desenvolvimento de uma metodologia de avaliação qualitativa dos impactos dos grandes empreendimentos como ferramenta para levantamentos etnogeográficos e para a execução de políticas públicas.

Os elementos indagativos dessas questões, consubstanciados na "socioeconomia de comunidades tradicionais"; "cultura e políticas públicas"; e "metodologia qualitativa", traduzem o vastíssimo universo de categorias e questões de pesquisa que desenvolvemos desde a década de 1980. Dito em outras palavras, traduzem os eixos condutores de nossa produção, seja oriunda de projetos e de orientações, seja da observação atenta de nossas vivências, dentre elas, a participação em um projeto de ação de política pública, objeto desse texto.

\footnotetext{
${ }^{1}$ A Petrobras se instalou em Sergipe na década de 1960, estabelecendo um marco de seu desenvolvimento com abertura de estradas, construção de terminais e dutos, dentre outras estruturas instaladas na região litorânea como planta de fertilizantes nitrogenados e fábrica de cimento.
} 
O artigo traz, pela exposição de uma vivência conduzida por oficinas, os elementos constitutivos da metodologia desenvolvida, adaptada para o levantamento das referências culturais e a construção da cartografia cultural de um grupo de jovens oriundos de nove povoados e da sede do município de Japaratuba/Sergipe. A oficina constou da primeira atividade do projeto "Japaratuba em Rede: Juventude, cultura e cadeias produtivas", desenvolvido pelo Instituto Banese, por meio de patrocínio resultante da seleção pública do edital "Integração Comunidades Petrobras 2013 Nordeste" e, em seu arcabouço, estavam presentes os eixos condutores de nossas pesquisas, razão pela qual aceitamos participar, sobretudo pelos desafios postos pelas orientações do projeto, quais sejam: a escala, os sujeitos e os instrumentais da pesquisa.

Embora o município de Japaratuba se situe na zona litorânea, como exposto, objeto de recentes estudos, nossas incursões foram, até então, balizadas pela abordagem regional $^{2}$. O município de Japaratuba foi eleito pelo proponente por guardar em sua história e tradição muito das culturas indígena, portuguesa e, em especial, da matriz africana. Face a essa realidade, o Projeto apresentou como argumento/tese que a educação profissional de jovens constituiria ação importante no fortalecimento das identidades culturais e na manutenção do patrimônio cultural do município, tendo sido proposto para ser executado em dois anos e em três etapas: i) o conhecimento e a identificação do potencial dos jovens, no que diz respeito à nossa atuação e objeto desse artigo; ii) a realização de oficinas de criatividade, comunicação e cultura digital e de gestão cultural; e iii) a criação de uma linha de produtos de comercialização de moda, decoração e ambientação e utilitários, inspirada nas referências culturais da cidade.

A partir dessa exposição, delineia-se nosso desafio em atuar em um projeto cuja escala local exige novos olhares para o desenvolvimento e para a dimensão da cultura e, ainda, distinto de pesquisa acadêmica, com o propósito de desenvolvimento de ações previamente estabelecidas. O desafio foi aceito pela possibilidade de prospectar, no sentido de mensurar o valor das expressões culturais e, especialmente, constatar se elas dão sentido às práticas dos jovens participantes do projeto.

Aliás, a delimitação de jovem como sujeito da pesquisa e o contato por meio de oficinas constituíram recortes metodológicos que não haviam sido considerados até então em

\footnotetext{
2 Citando apenas os projetos mais relevantes, atuamos e coordenamos pesquisas sobre a cultura como dimensão do desenvolvimento do Baixo São Francisco; realizamos um Inventário das expressões culturais de Sergipe, bem como das festas populares, turismo e políticas de cultura nos festejos dos ciclos juninos e natalinos.
} 
nossas investigações, direcionadas, sobretudo, para pessoas mais idosas e para representantes das comunidades. De acordo com o Projeto, os jovens enquadram-se na faixa etária de 18 a 29 anos, mas o critério de seleção privilegiou aqueles que direta ou indiretamente, pelas suas famílias e suas comunidades, "têm na manutenção de suas práticas culturais suas formas de reprodução simbólica do mundo da vida e são responsáveis por manterem vivas as expressões culturais locais e regionais de Japaratuba" (ABRAMOVAY; ESTEVES, 2007, p. 3). Com esse balizamento, foram selecionados 50 jovens de 16 a 28 anos, considerando os determinantes simbólicos, materiais, históricos e políticos que delimitaram os objetivos propostos.

A realização de oficina como instrumento de pesquisa não constituiu novidade em nossas investigações, mas sim, a duração e os objetivos. Em 2009, realizamos oficinas com oito horas de duração, com os pesquisadores que atuaram no inventário das expressões culturais de Sergipe (VARGAS, 2009) e, em 2014, em comunidades de pescadores do litoral sergipano, com duração média de seis horas, contando com a participação de homens e mulheres, sejam elas crianças, jovens e adultos, os quais expuseram suas referências, base que serviu para refletirmos patrimônio e identidade em nível de suas localidades e o impacto de grandes projetos em nível regional (VARGAS, 2015a; 2015b; 2015c). Portanto, a realização de vinte horas de oficina, conduzidas em duas turmas, nas sextas e nos sábados dos meses de fevereiro e março de 2015, constituiu na primeira experiência de longa duração com os mesmos sujeitos. A ação oportunizou o convívio que possibilitou a compreensão da realidade dos jovens participantes do projeto, sujeitos comprometidos com práticas culturais pulsantes no município de Japaratuba; a apreensão de seus referentes patrimoniais e identitários; o desenvolvimento de uma metodologia para captação do conhecimento e trato com o patrimônio cultural e este na construção das identidades, i.e., captação das expressões culturais e do sentido da cultura para os sujeitos em questão; e ainda, a construção de uma cartografia cultural referenciada pelos conteúdos levantados e pelas técnicas executadas na oficina. Assim sendo, são esses conteúdos que trazemos no presente artigo.

Se é possível uma síntese, podemos distinguir três etapas que se interpuseram para o alcance dos objetivos e das metas da oficina realizada e que resultaram na metodologia proposta. A primeira referiu-se à utilização de metodologias já aplicadas nos diversos momentos da oficina $(2009 ; 2011 ; 2014 ; 2015 a ; 2015 b ; 2015 c)$, acrescida da introdução de novos procedimentos, que consistiu na realização de quatro oficinas com duração media de 5 
horas cada, encadeadas pelas seguintes temáticas que nomeiam cada um dos quatro momentos, quais sejam: i) conhecimento; ii) reconhecimento; iii) praticas e vivências; e iv) pertencimento. A segunda atividade/etapa formou-se com a análise do material gráfico e textual produzido pelos jovens, com base nos referentes criados por Bardin (1977); Kozel (2005) e Vargas op. cit., o que possibilitou, num terceiro momento, a construção da cartografia cultural (VARGAS, 2015d).

Bardin op. cit. privilegia a análise de conteúdo que oportuniza a compreensão das características dos conteúdos e suas estruturas postos pelos fragmentos das mensagens levantadas, no nosso caso, muitos desenhos, textos e filmes - compreendidos, inclusive, com auxilio das encenações, das danças, das performances executadas, enfim, pela leitura da expressão corporal.

Kozel op. cit. foca na análise dos desenhos e, assim, nos auxiliou na interpretação dos conteúdos (elementos da natureza; elementos construídos; elementos "marcos" sejam eles naturais ou construídos; os planos das representações, dentre outros), importantes para a apreensão das referências maiores expostas em desenhos, quais sejam o patrimônio cultural vinculado às identidades dos jovens participantes do projeto Japaratuba em Rede.

Vargas op. cit. traz a análise de conteúdo para o tratamento qualitativo e quantitativo do repertório inventariado, categorizando as expressões culturais em "tradicionais enraizadas", como aquelas herdadas e mantidas tal como apropriadas no passado e "ressignificadas/contemporâneas", aquelas cuja evolução apresenta variações na composição e na estrutura, mas podem também corresponder a expressões novas, recentemente apropriadas (2011, p. 102). O material produzido nas oficinas foi tratado e exposto graficamente em quadros que traduzem a intensidade de ocorrência dos conteúdos, ou seja, as referências maiores expressas pelos jovens do projeto. Acrescentam-se a ampliação e adaptação das citadas oficinas realizadas nas comunidades litorâneas (VARGAS, 2015b), que tiveram como temas/conteúdos condutores, "Minha vida no Povoado" e "Minhas Referências", muito significativos para a apreensão e para a análise do patrimônio e da identidade.

Foi possível, ainda, identificar os elementos/signos ou "marcas" da paisagem e apreende-los como topofílicos ou topofóbicos ${ }^{3}$ (BERQUE, 1998; BONNEMAISON 2002; TUAN, 1980; 1983), qualidades essas que acreditamos serem importantes para a produção de

\footnotetext{
3 Topofilia é "o elo afetivo entre a pessoa e o lugar ou ambiente físico" e Topofobia o seu oposto (TUAN, 1980).
} 
produtos culturais, meta a ser alcançada pelo Projeto Japaratuba em rede, que se viabilizou com sucesso.

Assim posto, justificamos nossas motivações e os balizamentos metodológicos nessa introdução e apresentamos, em seguida, o encadeamento das oficinas, a cartografia cultural e as considerações finais como partes integrantes deste estudo.

\section{O ENCA DEAMENTO DAS OFICINAS}

O encadeamento das oficinas realizadas na etapa inicial do "Projeto Japaratuba em Rede: Juventude, cultura e cadeias produtivas" tanto é exposto de forma a dar maior clareza à metodologia, como também serve de memória para a ação e para os seus produtores, os jovens de Japaratuba pois, apresentam-se os registros dos quatro momentos da oficina que objetivou a apreensão do conhecimento e do potencial dos jovens com relação à constituição de redes e cadeias produtivas de cultura.

O material produzido reuniu 83 desenhos e 46 textos (com ou sem desenhos) sobre o conhecimento e o reconhecimento de seus lugares e suas gentes; 36 textos e 22 apresentações de slides, filmes e performances sobre suas práticas $\boldsymbol{e}$ vivências e, 38 matrizes das expressões, manifestações e práticas daquilo que lhes pertence, do que apropriam como seu, ou seja, a matriz do pertencimento. A dinâmica de apresentação oral dos desenhos e dos textos não se restringiu a apresentações formais, pois foram estimulados e motivados a mostrarem-se pela emoção. Em todas as oficinas ocorreram encenações e demonstrações mais destacadas neste artigo, cujo significado ultrapassou o material textual produzido e entregue para ao Instituto Banese.

No primeiro momento, realizamos uma "exposição motivacional", a qual contou com a presença dos 50 jovens selecionados e constou de uma dinâmica introdutória sobre patrimônio e identidade em que pese valores e heranças individuais e coletivas. As outras oito oficinas foram realizadas em 2 turmas definidas por questões operacionais e de logística, realizando-se quatro para cada turma. Didaticamente, os objetivos são mais facilmente alcançados com grupos menores e, considerando as distâncias e condições das estradas, as oficinas para a primeira turma foram realizadas nas dependências da UAB/UFS Universidade Aberta/Campus Japaratuba da Universidade Federal de Sergipe, na sede do município, com a participação de jovens tanto da sede e como dos povoados Patioba, Forges, 
São José da Caatinga, Porteiras e Sapucaia. Já as oficinas para a segunda turma foram realizadas nas dependências da Escola Municipal de Badajos, com a participação de jovens deste povoado e de Sibalde, Várzea Verde e Caraíbas.

A "Oficina 1: conhecimento" teve como motivação a retomada do conteúdo da oficina motivacional, ocorrida com a presença de todos. Com exemplos do conteúdo escolar, da mídia e do cotidiano, o patrimônio foi demonstrado como: tudo que produzimos e que reconhecemos como importante; o que herdamos do passado e reconhecemos no presente; tudo que é importante e que queremos conservar; tudo que remete à nossa história e à nossa identidade, sendo esta construída pelas histórias de vida, pelo que vivemos no dia-a-dia e, portanto, que a identidade não se repete, pois é construída pelas coisas próprias de cada lugar. Essa oficina correspondeu ao momento de atenção ao outro, de descobertas dos outros; de conhecimento de 'nós' pesquisadores - conhecendo os sujeitos da 'pesquisa/ação' e, dos jovens estreitando os laços de convivência com a vizinhança, com os conhecimentos dos outros; uns com os outros.

A primeira atividade constou da apresentação afetiva. Com as cadeiras posicionadas em círculo, foi solicitado que cada participante se apresentasse no meio de todos, momento que causou certa tensão. Este foi o primeiro encontro com muita proximidade física, quando muitos estavam se encontrando pela segunda vez, ou seja, ainda estranhos. Outros, no entanto, já se conheciam, sobretudo aqueles da mesma procedência (Figuras 1 e 2).

Ao chegar o momento de se exporem, foi possível observar que se colocaram uns próximos aos outros de acordo com os povoados e, sempre que lhes era solicitada a participação de um que seria o primeiro de determinada localidade, ocorria uma troca de olhares e uma negociação entre eles, resultando, finalmente, em quem iria "se expor" primeiro. A família, os pais, os irmãos e o que fazem foram os conteúdos mais apresentados. Da parte gestual, registramos mãos nervosas que abanavam aceleradas ou se escondiam em bolsos e costas, vozes embargadas nos depoimentos das lutas e dos orgulhos de serem daquela nucleação, lágrimas de contentamento por estarem ingressando num projeto que ainda não sabiam bem o que viria a ser, mas que depositavam expectativas de mudanças - de boas mudanças!. 
Figura 1 - Início da oficina do Conhecimento com a turma da sede.

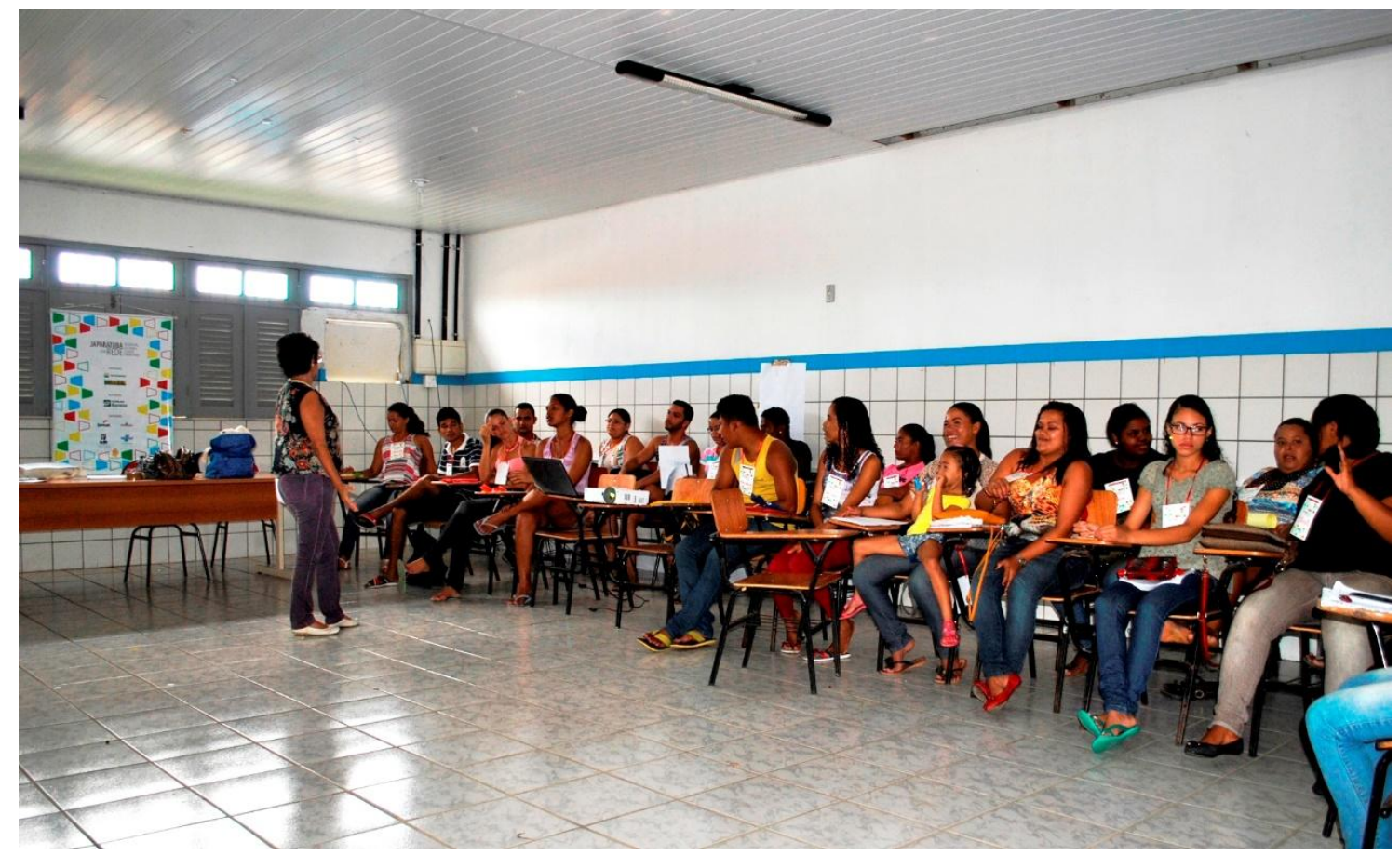

Fonte: Diego DiSouza (Equipe de comunicação do projeto Japaratuba em rede).

\section{Figura 2 - Início da oficina do Conhecimento com a turma do povoado Badajós}

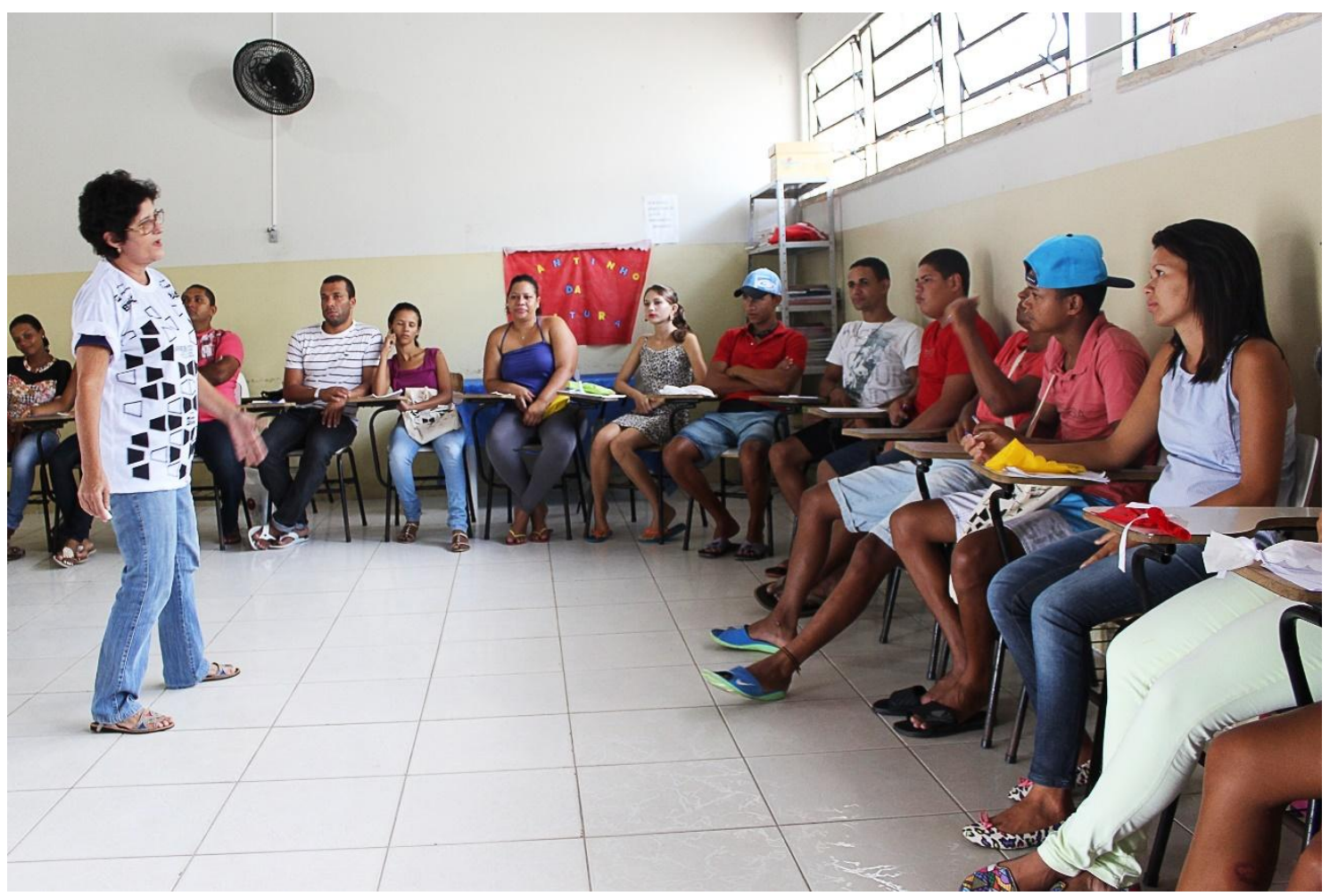

Fonte: Diego DiSouza (Equipe de comunicação do projeto Japaratuba em rede). 
Em seguida, foram distribuídos papel, lápis, borrachas e giz de cor e solicitado que desenhassem ou produzissem textos, ou ambos, com respostas para as seguintes perguntas motivadoras: i) O que o povoado (ou a sede) é para você?; ii) O que sinto, sentimento que tenho para com o povoado (ou sede)?; iii) Por que o povoado (ou sede) é especial para mim? A partir das referidas perguntas, foram confeccionados 49 desenhos e 28 textos com e sem desenhos.

A terceira e última atividade da oficina do conhecimento deu-se a partir da exposição dos desenhos e textos em um longo varal transversal ao espaço, seguida da exposição individual, agrupados por povoado/sede. Este ato correspondeu ao momento de atenção ao outro, de descobertas uns dos outros, enfim, de "conhecimento".

Os conteúdos que mais chamaram a atenção sobre os povoados e a sede nos textos foram: O povoado faz parte de mim; há pessoas importantes para mim; minha família; faz parte de minhas origens; é meu segundo coração; sinto orgulho de meu lugar; aqui (na sede) tem muitas manifestações e pontos culturais; fico feliz quando saio do meu povoado para outro lugar para representar nossa cultura (pastoril do Forges); é especial onde passei a infância com meus amigos.

Os desenhos, variados, foram expostos com falas emotivas, tais como: "Aqui é isso, aqui eu nasci; aqui é um lugar importante; essa e aquela são manifestações importantes". As primeiras falas da apresentação afetiva foram mais contidas (salvo de alguns que já se apresentaram com muita emoção) e, nesse momento, acrescentaram à filiação, ao amor e à família da primeira fala mais ênfase nas frases, gestos e impostação de vozes que sintetizam "orgulho de nascer aqui; amo o meu povoado".

A Oficina 2: reconhecimento iniciou com comentários (motivacionais) sobre a oficina 1, reforçando o conhecimento de seus lugares, o orgulho de serem o que são, de serem de onde são. De pronto, foi solicitado que se dispersassem para outras dependências do prédio, sozinhos ou em grupo, e que produzissem desenhos e/ou textos respondendo as seguintes perguntas motivadoras: i) Moram no povoado (ou sede) pessoas importantes para você? Quem? ii) Existem lugares ou prédios importantes para você? Quais; Por quê? iii) Ocorrem festas ou eventos importantes que mobilizam a comunidade e que são muito importantes para você e sua família? Quais? Como você e sua família participam?

Como resultado, foram confeccionados 34 desenhos e 18 textos com e sem desenhos que, como na oficina anterior, proporcionou-se a exposição destes em um grande 
varal (Figura 3). Tal momento correspondeu à confraternização dos jovens de um mesmo povoado com os demais e também à exibição lúdica do material produzido. Traduziu a exposição do que valorizam e do que reconhecem pela exposição de suas qualidades e de exposição de suas criatividades. Ocorreram além da exposição de seus textos e desenhos, apresentações de dança, teatro, samba de roda, quadrilha, sentinelas ${ }^{4}$ e sarandagem ${ }^{5}$. Palmas, muitas palmas, e sobretudo o reconhecimento e valorização do que fazem e o que são. O que chamou a atenção foi o quanto as expressões tradicionais enraizadas são importantes para esses jovens, também participantes e produtores de manifestações ressignificadas e contemporâneas.

\section{Figura 3 - Varal da oficina do Reconhecimento com a turma do povoado Badajós}

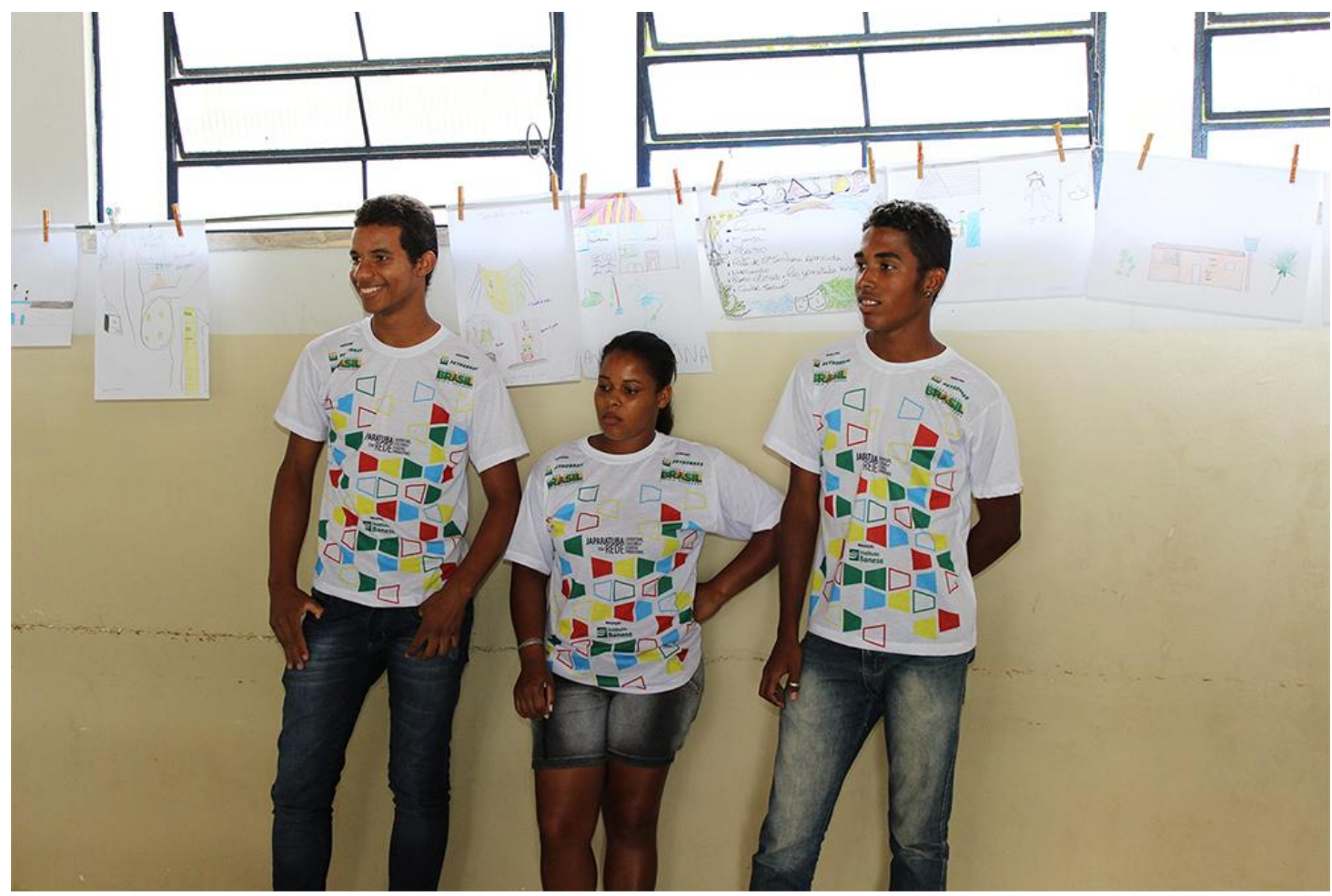

Fonte: Diego DiSouza (Equipe de comunicação do projeto Japaratuba em rede).

\footnotetext{
${ }^{4}$ Sentinela ou os velórios no interior de Sergipe, ato de velar os defuntos com cantos e rezas. Ver CARVALHO DÉDA, 2001. 5 Sarandagem ou sarandaia: brincadeira popular com objetivo de "acordar São João" no dia 31 de maio, que
em bloco percorrem as ruas do lugar. Ver Agenda Cultural, 1997.
} 
Dentre as expressões e manifestações tradicionais enraizadas reconhecidas e valorizadas foram destaque: o maracatu ${ }^{6}$, o maculele $\hat{e}^{7}$, o cacumbi $^{8}$, o pastoril ${ }^{9}$, a dança afro, a sarandagem, as festa das cabacinhas ${ }^{10}$, o artesanato de palha, o cipó e a pesca, as festas religiosas e dos padroeiros. Já dentre as expressões e manifestações ressignificadas e contemporâneas foram destacados: o Festival de Arte Arthur Bispo do Rosário, os grupos de dança moderna, as quadrilhas, as catadoras de mangaba e o teatro. Algumas das expressões foram recorrentes nos desenhos como pode ser observado na Figura 4, uma colagem daqueles que mais se repetiram. Da esquerda para a direita, um par quadrilheiro com balão, fogueira e lua, remete aos festejos de São João; a procissão adentrando a igreja católica às festas de padroeiros; os dançantes em círculo às danças de roda; os componentes do folguedo Guerreiros e, abaixo, a rainha e o rei do Cacumbi.

\section{Figura 4 - Desenhos produzidos durante as oficinas}

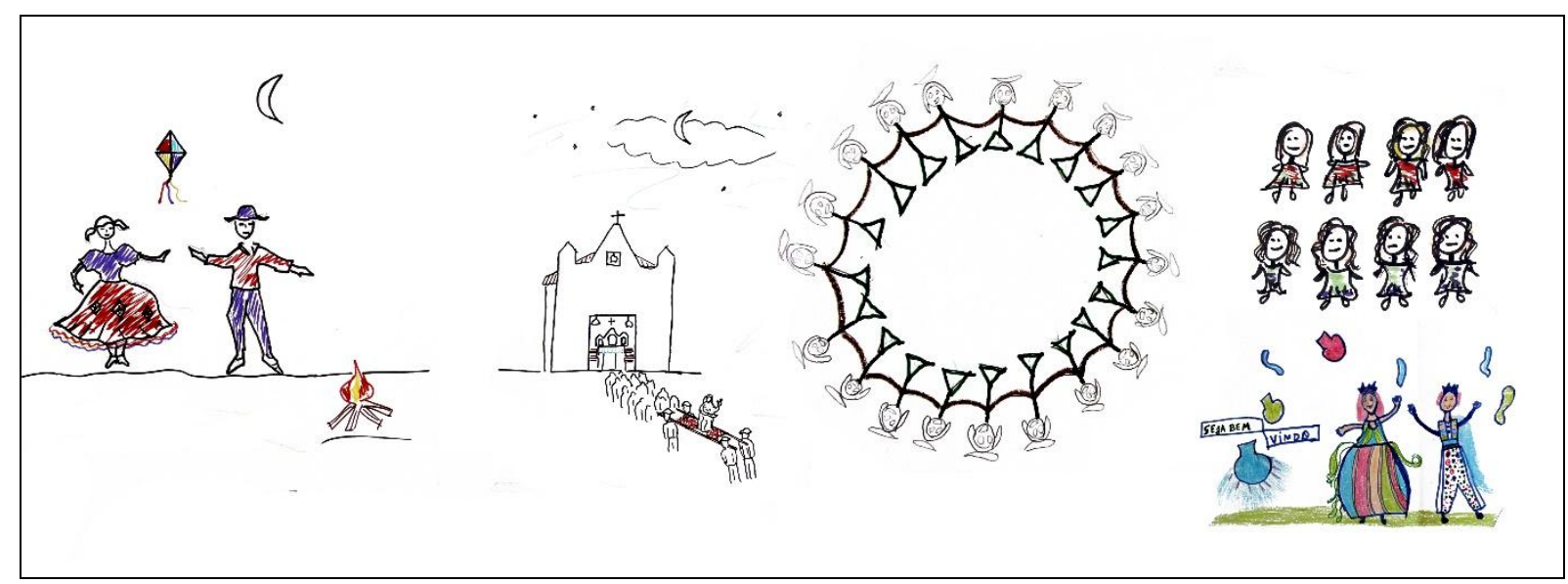

Fonte: Oficina Projeto Japaratuba em Rede. Org,: Equipe de comunicação do Projeto.

\footnotetext{
${ }^{6}$ Maracatu: folguedo dos festejos de Reis de origem africana que, em cortejo, revive o cerimonial das cortes africanas e bailam ao som de instrumentos de percussão. Ver Agenda Cultural, 1997.

${ }^{7}$ Maculelê: é uma representação popular, misto de jogo e dança de bastões. Ver CASCUDO, 2000.

${ }^{8}$ Cacumbi: folguedo popular com bailado brejeiro como variação de congada, guerreiro, reisado e ticumbi, que dança em homenagem a Nossa Senhora do Rosário e São Benedito. Ver Agenda Cultural, 1997.

${ }^{9}$ Pastoril: folguedo do ciclo natalino com música, dança e texto teatral em autos, que representa a peregrinação a Belém. Ver Agenda Cultural, 1997.

${ }^{10}$ Festa das cabacinhas: As cabaças de cera cheia de água são usadas como projétil uns contra os outros numa festa de molhação. Ver FERREIRA, 1986.
} 
Ao término das apresentações, foi distribuído um roteiro de pesquisa a ser cumprido, de preferência individualmente, cuja execução serviria de conteúdo para a realização da Oficina 3: Práticas e vivências. Tratou-se de um exercício dirigido baseado no instrumental aplicado para o inventário das expressões culturais de Sergipe e das festas dos ciclos junino e natalino (VARGAS, 2009; 2011; 2014). Os participantes poderiam trazer fotos, vídeos, gravações de voz, objetos, documentos e o que mais julgassem pertinente para demonstrar e expor. Assim sendo, uma das atividades deveria ser selecionadas para cumprir: 1) entrevistar um morador importante por sua prática para sua família ou para o povoado; 2) trazer o relato de uma expressão cultural que julgasse importante para sua família ou para o povoado; 3) levantar e trazer depoimentos orais e/ou documentos sobre pessoas, fatos ou expressões que julgassem relevantes para sua família ou para o povoado.

Apresenta-se a seguir o resumo do roteiro do exercício dirigido 1, minuciosamente exposto, de forma a auxiliá-los na sua execução da atividade selecionada com mais facilidade:

○ REGISTRO: nome, local, data. Do entrevistado, da expressão, enfim, do que selecionou para expor;

- QUEM: identificar quem e o que faz; há quanto tempo; se o que faz é sozinho ou em grupo; se é individual porém outros fazem; quantos fazem na localidade;

- DESCRIÇÃO: Como aprendeu; quem ensinou; fácil ou difícil; se é só de homem; só de mulher; se pode criança; se é um produto que se vende; se é um produto que precisa de matéria prima para fazer, qual, se é comprada ou existe na localidade. (Se, por exemplo, grupo de folguedo, cantor ou escritor, procure adaptar as perguntas de forma a descrever o que é);

- OCORRÊNCIA: se ocorre ou se faz durante todo o ano; em determinada época (qual); se tem data certa. (Se, por exemplo, folguedo ou festa religiosa, especificar data e período de apresentação);

- ORIGEM E EVOLUÇÃO: Como e com quem começou? Contar a história. Diferenças e semelhanças com relação a outros lugares que fazem a mesma coisa; Diferenças e semelhanças da forma de fazer no passado? Quando começou para o presente? Se ocorreram mudanças, foram em quê? $\mathrm{Na}$ forma, na composição, no significado de fazer? Especificar;

- SITUAÇÃO E DINAMISMO: O que significa para quem produz? O que significa para a comunidade? Enfrenta dificuldades? Quais? O que faz para manter? Recebe apoio? De que tipo e de quem?

- GERAÇÃO DE RENDA: Sim ou não? Se sim: Importância para quem produz, para o grupo, para o povoado, para o município. Envolve outras pessoas? (Exemplo 1- 
fornecedor, produtor, comprador, venda em feira, ou seja, está ligado a algum arranjo de produção para o comércio?) (Exemplo 2- compra materiais, se envolve outras pessoas, mas não é um arranjo de produção para o comercio).

A oficina 3: Práticas e vivências teve início com a retomada dos conteúdos das oficinas de Conhecimento e Reconhecimento, ressaltando aspectos positivos da diversidade e as possibilidades de fortalecimento entre eles; as possibilidades de se concretizar uma rede diversa com as suas potencialidades, com seus fazeres, e também com seus gestos e suas cores. Correspondeu ao momento em que se aguçou o interesse de 'ser pesquisador' (pelo encadeamento das questões do roteiro), a curiosidade, a persistência, a observação para com as práticas e vivências de suas famílias e dos moradores de seus respectivos locais.

A apresentação do que produziram com as orientações do Exercício dirigido 1 constou de vídeos, fotos e objetos apresentados em narrativas, alguns com a utilização power point com animação, outros embargando voz ao expor o sentido das cenas e das pessoas filmadas, outros com "relatório" nas mãos, explicando o percurso de sua consecução.

Foram expostos: 1. O candomblé de Japaratuba; 2. O Maracatu Renascer de Japaratuba; 3. O Maculelê de Japaratuba; 4. A quadrilha Cangaceiros da Boa; 5. As catadoras de mangaba do povoado Porteiras; 6. A etnocultura do povoado Patioba com vídeo e uma cartilha produzida pela Companhia Vale do Rio Doce; 7. A bonequeira do povoado Patioba; 8. O Reisado do Mestre Sabau do povoado São José da Caatinga; 9. D. Angelina, moradora antiga do povoado Sapucaia; 10. O Pastoril do povoado Forges; 11. Um artesão de artefatos de pesca do povoado São José da Caatinga; 12. A captura do mel de abelhas africanas no povoado Caraíbas; 13. A quadrilha e a cavalgada do povoado Caraíbas; 14. A festa da padroeira Nossa Senhora Aparecida do povoado Sibalde; 15. O grupo de dança e teatro Jovens Nova Atitude e a Associação Desenvolvimento Sócio Cultural Nova Atitude do povoado Sibalde; 16. A Corrida de Argola do povoado Sibalde; 17. O artesanato de crochê, bordado, vagonite e fuxico do povoado Badajós; 18. O artesão de cipó do povoado Badajós; 19. A lida com a produção de carvão no povoado Badajós; 20. A artesã de peneira do povoado Badajós; 21. O processo de produção da vassoura no povoado Badajós; 22. A história oral das famílias Rosário e Bispo do povoado Badajós.

O empenho e a criatividade dos jovens fez-nos ressaltar o conteúdo didático dessa atividade que, por sua vez, fez aguçar neles o interesse de ser pesquisador, pela curiosidade, persistência e necessário senso de observação para com as expressões que reconheceram 
como importantes. Ressalta-se que algumas produções foram feitas em grupo, sendo que sete participantes do povoado São José da Caatinga, integrantes do movimento Caatingart, não participaram da Oficina 3 por estarem participando na festa do padroeiro do povoado, São José, o que fizeram na Oficina 4, com apresentação de uma performance do grupo.

A oficina findou com a atividade de exposição das práticas e vivências de cada um e de sua família, correspondendo ao exercício dirigido 2. Eles foram solicitados a responder algumas perguntas que foram expostas oralmente e registradas na lousa. Foram postas as seguintes questões: Conjunto 1: i) Quais as atividades mais importantes em seu povoado (ou sede)?; ii) Quais as ocupações mais importantes em sua família?; iv) Você trabalha? Se Sim, em que?; v) Tem outras ocupações? Quais?; vi) O que mais gosta de fazer?; vii) $\mathrm{O}$ que menos gosta, ou não gosta de fazer?; Conjunto 2: i) Ocorrem/existem manifestações culturais importantes para a comunidade? ii) Sua família atua de alguma forma na realização da manifestação? Em qual (ou quais)?

Durante a exposição, muitos risos e muitas "descobertas" com expressões como: “Oh!”, “Ah!”, "Nossa!”, dentre outros. Com relação ao que gostam foi facilmente expresso em contraponto ao que não gostam. As atividades extrativistas e de serviços se destacaram entre eles bem como suas famílias. Ao término, o "mapa" das práticas e vivências dos jovens e suas famílias em seus respectivos locais de moradia, povoados e sede, começou a se esboçar e foi assim desenhado:

- Atividades mais importantes no povoado (e na sede) para as suas familias: Fabricação de vassoura; artesanato de palha; roça e agricultura; bituca (diarista na lida dos canaviais); casa de farinha; colheita de coco; olhar a vida dos outros; funcionário público; extração de petróleo; comércio; Festival Arthur Bispo do Rosário; artesanato de bordados.

- Voce trabalha?: Aproximadamente 40\% dos jovens trabalham. Eles são funcionários públicos; professores, produtores de cultura; comerciantes, dentre outros. A maioria é estudante.

- Tem outras ocupações?: 70\% dos jovens do Projeto têm outras ocupações, desde ajudar os pais em seus trabalhos/ofícios (roça, artesanato, comércio) até vendedores de catálogo, cabeleireiros e manicures. 
- $\quad$ O que mais gosta de fazer?: dançar (de forma geral), dançar quadrilha; jogar futebol; jogar vídeo game; lutar capoeira; cozinhar; bordar; fazer crochê; viajar; malhar; estar com a família; dar bom dia à mãe; ajudar a família; pintar; assistir filmes; dormir; ir a festas; estudar; trabalhar; louvar a Deus; ler; cantar; namorar; beber com amigos; estar com amigos; conectar-se às redes sociais.

- $\underline{O}$ que menos gosta?: Pessoas metidas; gente falsa; estupidez; acordar cedo; beber; ficar "parado"; ficar em casa; trabalhar para os outros; levar um fora; ficar sem internet; pegar água na fonte;

- Quais manifestações e expressões importantes para sua família e para o povoado?: Sarandagem; capoeira; festejos juninos; artesanato de bordado; festival Arthur Bispo do Rosário; dança; festa dos padroeiros; futebol; quadrilha; teatro; outras datas festivas; atividades da associação; religião evangélica; estudar; religião afro; carnaval; desfile cívico; festival gospel; queima de Judas.

A oficina 4: pertencimento teve início com a retomada dos conteúdos das oficinas anteriores, com foco na reflexão sobre seus posicionamentos com relação a: "eu e meu lugar; eu e minha família; nós do povoado (sede); nós do e no Projeto Japaratuba em Rede". Essa atividade correspondeu ao momento em que expressaram o que lhes pertence, pelo reconhecimento e valorização das práticas, sejam elas expressas pela subjetividade de seus cotidianos (o que gosto, o que não gosto; o que faço, o que faz minha família), sejam pela afirmação das tradições e das inovações das expressões e manifestações culturais conhecidas e reconhecidas ocorrentes em seus respectivos locais.

A primeira atividade correspondeu à exposição livre sobre a experiência com os exercícios dirigidos 1 e 2, a exposição de suas práticas; porque escolheram essa ou aquela pessoa ou atividade como significativas. O resultado foi excelente, pois todos compareceram com depoimentos surpreendentes, como se nos exercícios dirigidos tivessem trazido sínteses, resumos, partes. Com efeito, o cotidiano é surpreendente quanto ao quesito afetividade.

Ao término das exposições, foi-lhes solicitado que preenchessem uma matriz indicando as expressões e manifestações culturais importantes para eles, juntamente com seu grupo familiar, e para o povoado. O Quadro 1 mostra o extrato da matriz que apresentou mais de 90 expressões e manifestações tradicionais enraizadas e ressignificadas /contemporâneas. 
VARGAS, M. A. M.

Desvelando heranças, tradições e práticas de jovens de Japaratuba/SE-Brasil

Quadro 1 - Extrato da matriz: Expressões e Manifestações culturais importantes

\begin{tabular}{|l|l|l|l|l|l|}
\hline MANIFESTAÇÃO & Eu e família & Povoado & MANIFESTAÇÃO & Eu e família & Povoado \\
\hline \multicolumn{2}{|c|}{ Tradicional enraizada } & & \multicolumn{2}{c|}{ Ressignificada/Contemporânea } \\
\hline Festa de padroeiro & & & Coral & & \\
\hline Procissão & & & Pintor & & \\
\hline Novena & & & Dança & & \\
\hline Cultos afro & & & Vaquejada & & \\
\hline Cultos protestantes & & & Teatro & & \\
\hline Quadrilha & & & Etc., etc... & & \\
\hline Etc. etc... & & & & & \\
\hline
\end{tabular}

Fonte: VARGAS (2009).

As manifestações assinaladas mais reforçaram do que complementaram as expressões e manifestações expostas nas oficinas anteriores. Destacamos, todavia, os signos e as marcas expressos nessa matriz que reforçam as falas, os textos e os desenhos produzidos. Estes foram tomados como referentes de um sistema de categorias basilares para a execução de um mapa útil para a apreensão das expressões e manifestações culturais do município de Japaratuba e, portanto, para o trato da produção e da gestão da cultura intencionados pelo Projeto.

E, assim, e de forma a consolidar o mapeamento do patrimônio e das identidades dos jovens participantes do Projeto, foi iniciada a última atividade com a proposta aceita de realização de uma eleição em cuja cédula solicitava-se votação em duas expressões ou manifestações, quais sejam: 1- O que é mais importante para mim; 2- O que é mais importante em meu povoado (ou sede).

O resultado da eleição mostrou que as "preferências/referências" atestam o reconhecimento e a valorização dos saberes e dos fazeres comuns aos povoados e à sede municipal, com o seguinte quantitativo de votos: Festas de padroeiros (43), Festa de Reis e Cabacinha (42); Encontros, Festivais, Concursos, Festas temáticas a exemplo do Quilombofest e Festa da Mangaba (32); Quadrilhas (27); Outras Festas a exemplo do Mastro, Cavalgada, Cosme e Damião, São João, Sarandagem, Queima de Judas (14); Artesanato de palha, cipó, pesca (7). 
Os signos materiais e imateriais mais relevantes, os marcos e as marcas da paisagem, bem como as expressões comuns e as singularidades se interpõem, sinalizando os eixos de análise que colaboraram para a consecução da cartografia cultural, a qual será apresentada a seguir.

\section{A CARTOGRAFiA CULTURAL}

O encadeamento das oficinas proporcionou o entendimento do sentido da comunicação e do significado do repertório exposto i.e., e assim pudemos codificar e categorizar o material em múltiplos eixos de análise que permitiram categorizar o processo de constituição de redes, identificando caminhos, possibilidades, aproximações e singularidades aqui expostos.

Desse modo, a paisagem pode ser apreendida como um sistema visual holístico tanto quanto marcos geossimbólicos individualizados na paisagem, tal como cunhado por Jöel Bonnemaison op. cit. Para ele, o geossímbolo remete a um determinado lugar, território ou região. Também, foi possível perceber uma "paisagem marca e uma paisagem matriz", tal como expressada por Augustin Berque op. cit. Dos constitutivos da primeira, tem-se a aparência dos elementos da paisagem e da segunda, a categorização da paisagem que faz sentido como patrimônio.

De forma complementar à nossa avaliação, tomamos o sentido de topofilia dado por Yi- Fu Tuan op.cit., que demonstra os sentimentos de amor das pessoas para com o meio ambiente e que chama a atenção para o lar, o quintal, o local de nascimento, por exemplo, como lugares íntimos que são evocados pela sensibilidade daqueles que os experienciam. Com essas colocações, ele corrobora com os referentes que ora apresentamos acrescidos das singularidades próprias de um determinado lugar ou de uma determinada pessoa de um lugar, o que não quer dizer que são únicos. Com intuído de destacar os povoados, eles são apresentados no Quadro 2. 
VARGAS, M. A. M.

Desvelando heranças, tradições e práticas de jovens de Japaratuba/SE-Brasil

Quadro 2 - Gentes e lugares

\begin{tabular}{|c|c|c|}
\hline Povoados/Sede & Pessoas & Lugares/elementos da paisagem \\
\hline Sede & $\begin{array}{l}\text { Janete Santos, Maria de Souza (Dona), } \\
\text { Arthur Bispo do Rosário, Everton dos } \\
\text { Santos, Gilney Marques, D. Nininha, } \\
\text { Edileusa. }\end{array}$ & $\begin{array}{l}\text { Praça da Matriz, } \\
\text { Candomblé, Coqueiro. }\end{array}$ \\
\hline Patioba & $\begin{array}{l}\text { D. Julita (Juliana), Antônia Rosa, D. Ica } \\
\text { (Wiclea), José Francisco (finado } \\
\text { Paizinho). }\end{array}$ & Praça, Figueira. \\
\hline Forges & D. Rezelda Batista. & Minador, Escola Municipal. \\
\hline São José da Caatinga & $\begin{array}{l}\text { Valdemar, Mestre Sabau, Mestre Jovi, } \\
\text { Pai Adão, família Prado. }\end{array}$ & $\begin{array}{l}\text { Cactus, Estátua de São José, } \\
\text { Coqueiro. }\end{array}$ \\
\hline Porteiras & $\begin{array}{l}\text { Edileuza, Creuza, Jaqueline, Nilza, } \\
\text { Jenilde, Juscilene. }\end{array}$ & $\begin{array}{l}\text { Praça, Posto de Saúde, Escola } \\
\text { Municipal, Mangabeiras. }\end{array}$ \\
\hline Sapucaia & Maria Angelina (D. Du), D. Berna-dete. & $\begin{array}{l}\text { Praça da Pitombeira, } \\
\text { Social, Escola Municipal. }\end{array}$ \\
\hline Caraíbas & Jose Hora, D. Val. & Roças, Associação. \\
\hline Sibalde & $\begin{array}{l}\text { Edivan, Carivaldo, D. Lucia Santos, } \\
\text { Manoel dos Santos, Selma, Adriana, } \\
\text { Ana Carolina, D. Maria Velha. }\end{array}$ & Largo, Lagoa, Clube Social. \\
\hline Várzea Verde & & Campo de Futebol, Coqueiro. \\
\hline Badajós & $\begin{array}{l}\text { Tereza Bispo, D. Gildete, D. Maria } \\
\text { Izabel, D. Lucilia, D. Maria Iolanda } \\
\text { (Nêga), Zé Luiz. }\end{array}$ & $\begin{array}{l}\text { Cruzeiro, Praça, Matas, Escola } \\
\text { Municipal, Coqueiro. }\end{array}$ \\
\hline
\end{tabular}

Fonte: Vargas, Maria A. M. Oficina Patrimônio Cultural e Identidade, 2015.

Observa-se que as percepções são destacadas e dentre elas: o coqueiro se sobressai, principalmente, nos desenhos, como marca da paisagem, embora os tratos com o cultivo não sejam tomados como atividade relevante; a lagoa do povoado Sibalde, por ter seu entorno degradado, além de ser um local guardado na memória como lazer da infância; o "minador" (ou seja, a cisterna) do povoado Forges marca a paisagem, mas também sinaliza que o lugar ainda não é abastecido com água e, assim, fica nítido que "pegar água na fonte" é tarefa que os jovens não gostam. 
Todavia, foram claramente perceptíveis e facilmente identificados os elementos norteadores e constitutivos do patrimônio e da identidade, o que permitiu estabelecer três eixos de análise, quais sejam:

- Herança rural: identificada na extração e processamento da mangaba no povoado Porteiras; apicultura no povoado Caraíbas; casa de farinha no povoado Badajós; artesanato de pesca no povoado São José da Caatinga; e o artesanato de palha em vários povoados;

- Tradições: no "brincar" em folguedos como no Guerreiro do povoado São José da Caatinga; no Maculelê, Cacumbi, Chegança, Taieira e Maracatu da sede; na Corrida de Argola do povoado Sibalde; no fazer Bonecas no povoado Patioba; na Festa de Reis da Sede e nas festas de padroeiros em todos os povoados;

- Contemporaneidades: na dinâmica de refazer e inventar, sobretudo, festas tais como a Festa da Mangaba do povoado Porteiras; Bloco de carnaval do povoado Sibalde; a Festa Arrochacha do povoado Badajós; o Quilombofest do povoado Patioba; além das quadrilhas (quase todos dançam) e os grupos de teatro e dança afro e contemporânea, respectivamente, dos povoados São José da Caatinga, Patioba, Sibalde e Sapucaia.

As conexões e os caminhos para a rede dos jovens foram, assim, mapeados em três eixos que traduziram a dimensão cultural das expressões e manifestações por eles vivenciadas e valorizadas. A síntese é apresentada no Quadro 3.

\section{Quadro 3 - Dimensão cultural das expressões e manifestações}

\begin{tabular}{|l|l|l|}
\hline HERANÇA RURAL & SABER FAZER & $\begin{array}{l}\text { Artesanato de palha, cipó e pesca; casa de } \\
\text { farinha; roças; extrativismo da mangaba e das } \\
\text { palhas; coco; manga; doces e mel. }\end{array}$ \\
\hline TRADIÇÕES & FESTAR & $\begin{array}{l}\text { Festas religiosas dos padroeiros; festas } \\
\text { populares do entorno das comemorações } \\
\text { católicas e afro; festas pagãs; festas gospel; } \\
\text { festivais; encontros; concursos. }\end{array}$ \\
\hline CONTEMPORANEIDADE & CONECTAR & $\begin{array}{l}\text { Escolas; Associações; Redes sociais; Grupos } \\
\text { de teatro; Grupos de dança; Quadrilhas. }\end{array}$ \\
\hline
\end{tabular}

Fonte: Vargas, Maria A. M. Oficina Patrimônio Cultural e Identidade, 2015. 
Os eixos da análise traduzem as expressões e manifestações já consolidadas, ou seja, as tradições enraizadas das festas e dos saberes herdados da tradição rural e, também, as expressões praticadas nos dias atuais, muitas delas reivindicadas pelos jovens em seus cotidianos como redes sociais e outras já pertencentes aos seus territórios familiares como os grupos de danças, em especial, as quadrilhas.

O saber fazer da herança rural remeteu-nos a visualizar as possibilidades de redes, como mostra o Quadro 4. O artesanato de palha é unanimidade como um saber fazer passado de geração a geração, seguido do respeito às rezadeiras e benzedeiras, desconhecidas apenas pelos jovens participantes dos povoados Caraíbas e São José da Caatinga e, pela lida com os coqueirais sem referência na sede e em São José da Caatinga.

Quadro 4 - Herança rural: possibilidades de redes

\begin{tabular}{|c|c|c|c|c|c|c|c|c|c|c|}
\hline $\begin{array}{l}\text { LOCALIDADES } \\
\text { EXPRESSÕES }\end{array}$ & Sede & $\begin{array}{l}\text { São } \\
\text { José }\end{array}$ & Sapucaia & Patioba & Forges & $\begin{array}{c}\text { Var. } \\
\text { Verde }\end{array}$ & Badajós & Porteiras & Sibalde & Caraíbas \\
\hline Art. Palha & & & & & & & & & & \\
\hline Rezadeira & & & & & & & & & & \\
\hline Coco & & & & & & & & & & \\
\hline Cavalgada & & & & & & & & & & \\
\hline Vaquejada & & & & & & & & & & \\
\hline Roças & & & & & & & & & & \\
\hline Even. Agrop. & & & & & & & & & & \\
\hline Manga & & & & & & & & & & \\
\hline Mangaba & & & & & & & & & & \\
\hline
\end{tabular}

Fonte: Vargas, Maria A. M. Oficina Patrimônio e Identidade, 2015.

Alguns aspectos são merecedores de atenção. $\mathrm{O}$ primeiro deles diz respeito à fragilidade do artesanato de palha, de cipó e de pesca com relação à disponibilidade de matéria prima, encontrada em matas e lagoas, mas, sobretudo, em relação aos inúmeros artesãos que ainda sobrevivem da produção de vassouras, chapéus e artefatos de pesca. Observamos que os povoados estão, em sua maioria, envoltos por áreas de cultivo e que o da cana-de-açúcar ocupa extensas áreas. Assim, os cipós, as taquaras, os oiricurizeiros, dentre 
outros, são cada vez mais raros. Em Badajós, identificamos que se compra a matéria prima de um vendedor que vai até o povoado, mas sem informação de onde ela vem - e eu indaguei: “até quando?!". O mesmo pode ser afirmado para o extrativismo da mangaba com a diminuição da vegetação nativa, pondo em risco as catadoras da fruta, sujeitos sociais que surgiram recentemente em Sergipe, com a organização em associações locais e cooperativas. No município de Japaratuba, destacam-se as catadoras do povoado Porteiras.

O segundo, diz respeito aos tratos com os coqueirais, com as rezadeiras e benzedeiras, os quais se referem a fazeres e saberes tradicionais. Os coqueiros foram amplamente desenhados, mas sua produção não surgiu em relatos associados aos referentes maiores. Dessa forma, permanecem como referentes da paisagem e traduzem para os jovens uma marca da tradição, como já colocado anteriormente. As rezadeiras e benzedeiras "surgiram" na Oficina 4, com o preenchimento da matriz de expressões com relatos interessantes sobre parentes, vizinhos, todos mais velhos e, portanto, também como referentes de valores tradicionais - porém, "em extinção".

As tradições das festas são fortemente expostas tanto quanto as ressignificações em suas estruturas e formas de manifestar. O Quadro 5 apresenta todas as celebrações citadas, comentadas e votadas.

Nele, visualiza-se no primeiro bloco de festas de padroeiro, tais como a de São João e o Forró, ocorrentes em todas as localidades, sendo este último a ressignificação dos festejos juninos tradicionais. A participação em quadrilhas juninas é tão importante para os jovens que foram tratadas como atividade que potencializa a conformação de rede, tratada a seguir. Na extremidade inferior do quadro, estão duas manifestações tradicionais: o carnaval com banda, apenas no povoado Badajós, e a festa do folguedo de bacamarteiros ${ }^{11}$, que sucede apenas na sede.

Observa-se, de pronto, que as festas surgem com a força do sentido de festar: extravasar, rezar, competir, brincar, extrapolar! Mas nesse contexto de ruptura do cotidiano (será?), as festas religiosas dos padroeiros aparecem, tal como à época de seus pais e avós, como as manifestações culturais mais importantes para eles, para suas famílias e para o povoado. Mantem-se a tradição de reverenciar os padroeiros com mudanças nas atividades de

\footnotetext{
${ }^{11}$ Bacamarteiro: folguedo popular organizado em batalhões sob o comando de sargentos que cantam, dançam com o tiro de bacamarte, em homenagem ao Santo de devoção. Ver Agenda Cultural, 1997.
} 
entorno, sobretudo no que a Arquidiocese de Sergipe fez distinguir, nomeando-as de atividades populares pagãs.

Quadro 5 - As tradições, as festas e as ressignificações

\begin{tabular}{|c|c|c|c|c|c|c|c|c|c|c|}
\hline $\begin{array}{l}\text { LOCALIDADE } \\
\mathrm{S} \\
\text { Festas/manif. }\end{array}$ & Sede & $\begin{array}{l}\text { São } \\
\text { José }\end{array}$ & $\begin{array}{c}\text { Sapucai } \\
\text { a }\end{array}$ & $\begin{array}{c}\text { Patiob } \\
\text { a }\end{array}$ & $\begin{array}{c}\text { Forge } \\
\mathrm{s}\end{array}$ & $\begin{array}{l}\text { Varzea } \\
\text { Verde }\end{array}$ & $\begin{array}{c}\text { Badajó } \\
\text { s }\end{array}$ & $\begin{array}{c}\text { Porteira } \\
\mathrm{s}\end{array}$ & $\begin{array}{c}\text { Sibald } \\
\mathrm{e}\end{array}$ & Caraíbas \\
\hline Padroeiro & & & & & & & & & & \\
\hline São João & & & & & & & & & & \\
\hline Forró & & & & & & & & & & \\
\hline Quadrilha & & & & & & & & & & \\
\hline Paixão Cristo & & & & & & & & & & \\
\hline Festival, Enc. & & & & & & & & & & \\
\hline $\begin{array}{l}\text { Cosme e } \\
\text { Damião }\end{array}$ & & & & & & & & & & \\
\hline Sarandagem & & & & & & & & & & \\
\hline Cabacinha & & & & & & & & & & \\
\hline Reisado & & & & & & & & & & \\
\hline Pífano & & & & & & & & & & \\
\hline Micareta & & & & & & & & & & \\
\hline Capoeira & & & & & & & & & & \\
\hline Busca Mastro & & & & & & & & & & \\
\hline Quei. Judas & & & & & & & & & & \\
\hline Pastoril & & & & & & & & & & \\
\hline S. de roda & & & & & & & & & & \\
\hline Bacamarte & & & & & & & & & & \\
\hline Carnaval & & & & & & & & & & \\
\hline
\end{tabular}

Fonte: Vargas, Maria A. M. Oficina Patrimônio e Identidade, 2015. 
Dentre as festividades religiosas, a Festa de Reis, que ocorre na sede, foi considerada pelos participantes dos diversos povoados como muito importante, principalmente por ocorrer concomitante à Festa das Cabacinhas, quando se apresentam diversos grupos de folguedos, danças, teatro e a tradicional coroação do rei e da rainha do Cacumbi.

As manifestações contemporâneas foram apreendidas pela identificação de grupos e pelas atividades com potencial para aproximações e conexões em rede, como apresentado no Quadro 6.

Quadro 6 - Grupos e representações: aproximações em rede

\begin{tabular}{|l|l|l|l|l|l|l|l|l|l|l|}
\hline LOCALIDADES & Sede & São & Sapucaia & Patioba & Forges & $\begin{array}{l}\text { Varzea } \\
\text { Verde }\end{array}$ & Badajós & Porteiras & Sibalde & Caraíbas \\
\hline Quadrilhas & & & & & & & & & & \\
\hline Religião católica & & & & & & & & & & \\
\hline Religião Afro & & & & & & & & & & \\
\hline Grupo de dança & & & & & & & & & & \\
\hline Religião Evangélica & & & & & & & & & & \\
\hline Escolas & & & & & & & & & & \\
\hline Associações & & & & & & & & & & \\
\hline Grupo de Teatro & & & & & & & & & & \\
\hline
\end{tabular}

Fonte: Vargas, Maria A. M. Oficina Patrimônio e Identidade, 2015.

Esse conjunto de expressões foi exposto para a ação das futuras atividades do Projeto, as quais, entendemos, apresentaram em sua natureza características e potencialidades de agregação em teia, ou seja, em "rede". As quadrilhas lideram como potenciais instrumentos de agregação por serem importantes para quase todos, mas, por outro lado, as três associações identificadas e suas distintas áreas de atuação são exemplos práticos a se discutir pelos jovens construtores de cadeias produtivas de cultura do município. $\mathrm{Na}$ sequência desse raciocínio, as religiões e as escolas podem ser encaradas como tradutoras de valores tradicionais, assim como os grupos de teatro e dança como emissores de novas posturas. 
Com efeito, diante do material exposto, os jovens participantes do Projeto demonstraram identidade com o território e com o repertório cultural deste território. Eles se relacionam com grupos e representações que, em meio à identidade com o território, identificamos novas territorialidades. É o caso, por exemplo, de integrantes do Movimento Catingaart do povoado São José, que fazem parte da Quadrilha Cangaceiros da Boa, juntamente com jovens da sede e do povoado Badajós. Com a quadrilha, eles representam seus lugares, o município e se identificam. O mesmo ocorre com suas práticas e representações com relação às religiões e aos grupos de teatro.

\section{CONSIDERAÇÕES FINAIS}

Os conteúdos desse estudo foram mais 'tecidos' do que apresentados. A lógica dos caminhos percorridos foi exposta pela intenção de trazer a construção dessa oficina pela prática de outras, realizadas com instrumentais de pesquisas qualitativas. A retrospectiva permite apreender esse conjunto de instrumentais, consubstanciado na oficina para o Projeto Japaratuba em Rede, ora apresentado como "metodologia Vargas". Todavia, esse conjunto de atividades possibilita a interpretação sob diferentes "olhares" e sob diferentes leituras e, assim, não se espera a sua apreensão como procedimentos que engessem a pesquisa. Dito em outras palavras, que sejam tomados como norteadores, inspiradores e motivadores para a definição das técnicas e dos instrumentais da pesquisa.

Procuramos trazer "à tona" o mapeamento das expressões culturais extraído da análise dos conteúdos produzidos nas oficinas como um sistema de categorias, balizado por objetivos explícitos, fundamentais para o encadeamento dos conteúdos e instrumentais. Além disso, ficou clara a produção de um banco de dados, matrizes e material imagético que possibilitaram a apreensão da realidade complexa das dimensões da cultura, o suficiente para assumirmos recortes analíticos balizados pelos eixos da herança rural, das tradições e das manifestações contemporâneas.

Os eixos de análise apresentados traduziram um recorte específico para a realidade japaratubense estudada e, mais especificamente, um recorte "elaborado" para o atendimento dos objetivos do Projeto. Porém, o procedimento metodológico apresentado, preexistente para o levantamento de um sistema de categorias avaliativas do patrimônio e da 
identidade, mesmo com referentes definidos pelo "estudo de caso", se presta para o atendimento das necessidades e interesses específicos de outros estudos. É nesse sentido que se coloca que a metodologia não deve ser tomada como um encadeamento a ser seguido rigorosamente.

Assim sendo, apresentamos a cartografia cultural como expressão viva e múltipla, em constante produção e ressignificação, não somente vivenciada no presente pelos jovens participantes do Projeto, mas também retida em suas memórias e na paisagem. Tais jovens se apresentaram como ativos na dinâmica da cultura, pois, tanto as catadoras de mangaba confirmaram a antiguidade do fazer pelas avós até suas atuações no presente como sujeito social reconhecido, quanto os grupos de dança, múltiplos em suas expressões, se fazem reconhecidos como artistas locais. No entanto, chamou a atenção o quanto as expressões tradicionais enraizadas são importantes para esses jovens produtores e participantes de manifestações ressignificadas e contemporâneas.

Ficou claro, também, que a sistematização de informações sobre as expressões culturais não é tarefa fácil. Mas, a relativa rapidez de execução das oficinas e o elevado volume de informações, gerado por esse conjunto de procedimentos, habilita essa metodologia como ferramenta a ser considerada nas diversas etapas de execução de estudos que considerem a dimensão cultural e o seu tratamento em que pese as determinações simbólicas, materiais, históricas e políticas da dinâmica produção social. Nesse sentido, ressalta-se como vantajoso o curto espaço temporal, face ao volume de dados levantados e às possibilidades de análise.

Os caminhos percorridos pelos procedimentos desenvolvidos nas oficinas: 1 . Conhecimento; 2. Reconhecimento; 3. Práticas e vivências e 4. Pertencimento sinalizam, reforça-se, sua aplicação em outros estudos que se aplicam a levantamentos etnogeográficos (enraizamento, pertencimento, reconhecimento, memória, identidade, patrimônio, dentre outros), tanto quanto a avaliações no âmbito da produção, do sentido, da economia e das políticas de e para a cultura. Sob esse aspecto, denotam-se as diversas análises transversais que são possíveis de serem efetuadas a partir de eixos maiores e que, nesse exemplo, tiveram a intenção de expor a dinâmica da cultura, quais sejam as possibilidades de redes, as festas, as tradições, as ressignificações, as novidades, os signos, as marcas e as singularidades.

Enfim, pelo exemplo das heranças, tradições e práticas dos jovens de Japaratuba aqui expostas, entendemos que a opção por instrumentais múltiplos em que pese o uso de 
depoimentos, desenhos, textos, encenações, "pesquisa" e preenchimento de uma matriz (induzida) de expressões culturais, propulsores deste estudo, sirva como exemplo a ser proposto e executado em outras investigações qualitativas que objetivem levantar, dar visibilidade, compreender e analisar práticas, patrimônio e identidades.

\section{AGRADECIMENTOS}

Com esse texto retribuo a acolhida do PPGEO e agradeço pela bolsa CAPES/PNPD recebida.

\section{REFERÊNCIAS}

AGENDA CULTURAL. Danças e folguedos de Sergipe. Arcaju: BNB, 1997.

ABRAMOVAY M.; ESTEVES, L. C. G. et.al. (orgs). Juventudes: outros olhares sobre juventude: Ministério da Educação, SECAD-UNESCO, 2007.

BARDIN, L. Análise de conteúdo. Lisboa: Edições 70, 1977.

BERQUE, Augustin. Paisagem-Marca, Paisagem-Matriz: elementos da problemática para uma geografia cultural. In: CORREA, Roberto L.; ROSENDAHL, Zeny. (orgs). Paisagem, Tempo e Cultura. Rio de Janeiro: Eduerj, 1998, p. 84-91.

BONNEMAISON, Jöel. Viagem em torno do território In: ROSENDAHL, Z. ; CORREA, R. L. (orgs). Geografia cultural: um século. Rio de Janeiro: Eduerj, 2002, p. 83-116.

CARVALHO DÉDA, José de. Brefais e burundangas do folclore sergipano. 2. Ed. Maceió: Ed. Catavento, 2001.

CASCUDO, L. da Câmara. Dicionnário do folclore brasileiro. 9 ed. Revista, atualizada e ilustrada. São Paulo: Global, 2000.

DIEGUES, Antonio Carlos. Pescadores, camponeses, trabalhadores do mar. São Paulo: Ática, 1983.

FERREIRA, A. B.de H. Novo Dicionário da língua portuguesa. 2. Ed. Rio de Janeiro: Nova Fronteira, 1986.

KOZEL TEIXEIRA, Salete. Ressignificando as representações do espaço - as linguagens do cotidiano. In: X Encontro de Geografia de América Latina, 2005, São Paulo Anais... São Paulo: USP, 2005, p. 1-5. 
TUAN, Yi-Fu, Espaço \& Lugar: a perspectiva de experiência. Tradução de Lívia de Oliveira São Paulo: Difel, 1983.

TUAN, Yi-Fu. Topofilia: um estudo da percepção, atitudes e valores do meio ambiente. São Paulo: Difel, 1980.

VARGAS, Maria Augusta M DOURADO, Auceia M.; SANTOS, Rodrigo Herles dos. (Orgs.) Patrimônio e Identidade: nossas referências. Aracaju: EDISE, $2015 \mathrm{~b}$.

VARGAS, Maria Augusta M. (coord.). Grandes projetos e identidades locais: possibilidades e desafios das pequenas comunidades costeiras. Relatório final. Convênio: CNO/FAPESE/GRUPO DE PESQUISA SOCIEDADE E CULTURA/UFS. Aracaju: UFS, 2015a, 59 p.

VARGAS, Maria Augusta M. Cartografia cultural: patrimônio cultural e identidade dos jovens do município de Japaratuva/SE. Aracaju: Instituto Banese. 2015d.

VARGAS, Maria Augusta M. Festas patrimônio: os ciclos junino e natalino de Sergipe. In: Revista Ateliê Geografico, Goiania, v.8, n.2, 2014, p. 252-273.

VARGAS, Maria Augusta M. Mapeamento das identidades culturais e diagnóstico participativo. Relatório. Projeto Japaratuba em rede: juventude cultura e cadeias produtivas. Aracaju: UFS, abril 2015, 98 p.

VARGAS, Maria Augusta M. Território de identidade nos territórios de planejamento: heranças e construções em Sergipe. In: Revista Anpege v.7, n.1, 2011, p. 99-109.

VARGAS, Maria Augusta M.; NEVES, Paulo S. C. Inventario Cultural dos territórios sergipanos. Relatório. Aracaju: Seplan, 2009, 171p.

VARGAS, Maria Augusta M; DOURADO, Auceia M.; SANTOS, Rodrigo Herles dos. (Orgs). Práticas e vivências com a Geografia cultural. Aracaju: EDISE, 2015c.

\section{Autora}

Maria Augusta Mundim Vargas - Possui Graduação em Geografia pela Universidade Federal de Minas Gerais (UFMG), Mestrado em Geografia pela Universidade Federal de Sergipe (UFS) e Doutorado em Geografia pela Universidade Estadual Paulista Júlio de Mesquita Filho (UNESP). Atualmente é Docente no Programa de Pós-Graduação em Geografia da Universidade Federal de Sergipe (UFS) e Professora colaborado do Programa de Pós-Graduação em Geografia (PPGEO-UNIMONTES).

Artigo recebido em: 14 de março de 2017 